CLINICAL STUDY

\title{
Influence of gender, age and renal function on plasma adiponectin level: the Tanno and Sobetsu study
}

\author{
Takeshi Isobe, Shigeyuki Saitoh, Satoru Takagi, Hiroshi Takeuchi, Yu Chiba, Nobuo Katoh and \\ Kazuaki Shimamoto \\ Second Department of Internal Medicine, Sapporo Medical University, School of Medicine, S-1, W-16, Chuo-ku, Sapporo 060-8543, Japan \\ (Correspondence should be addressed to T Isobe; Email: isobet@sapmed.ac.jp)
}

\begin{abstract}
Design: The aim of this study was to determine the association between aging and adiponectin level from the aspect of the influence of renal function and sex hormones in humans.

Methods: Serum adiponectin and blood urea nitrogen (BUN) levels were measured in 964 subjects (372 males) aged 60.3 12.5 years. Testosterone and free testosterone levels were measured in 123 males, and estrone and estradiol levels were measured in 114 females. The subjects were divided into two age groups; 65 years of age or older (Age $\geq 65$ group) and less than 65 years of age (Age $<65$ group).

Results: Adiponectin level increased linearly with aging in males, whereas it increased dramatically in females until their 50s. The patterns of changes in adiponectin were similar to those in BUN. In multiple-regression analysis using adiponectin as a dependent variable BUN was selected as a significant independent variable in all subjects and in subjects in the Age $\geq 65$ group, whereas bioactive sex hormones were not selected.

Conclusions: A decrease in adiponectin clearance in the kidney may be the cause of high levels of adiponectin in the elderly. Adiponectin level seems to be influenced more strongly by BUN than by sex hormones and to be increased by a decline in renal function with aging.

European Journal of Endocrinology 153 91-98
\end{abstract}

\section{Introduction}

Adiponectin is a 244-amino-acid plasma protein (1) that was identified from a gene, apM1, specifically expressed in fat tissue. Adiponectin has been shown to circulate as a trimer, hexamer or higher-molecularmass form in the blood of healthy subjects and to be present at a high level of $5-10 \mu \mathrm{g} / \mathrm{ml}(2-6)$. It has been shown that the ratios among these forms determine their activity (7-9). There are also significant sex differences in the circulating concentrations of adiponectin and in the ratios of their subunits $(7,10)$. Differences between adiponectin levels were found in normotensive and hypertensive men with abnormal renal function, but not in women (10). It has been reported that the level is low in subjects carrying excessive organ fat and that the level increases with a reduction in body weight and is correlated negatively with body mass index (BMI) (3). In addition, adiponectin level has been shown to be correlated negatively with blood pressure and triglyceride level and positively with high-density lipoprotein (HDL) level and to be decreased in patients with hypertension (11) and hyperlipidemia $(12,13)$. It has also been shown to be correlated negatively with fasting plasma glucose (FPG) level, plasma glucose level $2 \mathrm{~h}$ after a meal and fasting insulin concentration $(14,15)$, and to be closely associated with insulin resistance $(16-20)$.

On the other hand, it has been reported that adiponectin levels are elevated in the elderly $(21,22)$. This seemingly contradictory finding that levels of adiponectin, which has anti-atherosclerotic properties, were elevated in elderly subjects who were presumed to have developed atherosclerosis due to the accumulation of risk factors is intriguing. Previous studies showed that there is an inverse relationship between adiponectin and creatinine clearance in essential hypertensives and that adiponectin level was increased in patients with a combination of decline of renal function and hypertension (10). It has also been reported that adiponectin level was increased in patients with end-stage renal disease (23) and that adiponectin level was positively associated with impaired renal function, assessed by urinary albumin-to-creatinine ratio, in patients with diabetes (24). However, the mechanisms by which adiponectin is metabolized and excreted are not known, 
and the relationship between renal function and adiponectin level in humans who are relatively healthy has not been determined. Most of serum testosterone binds to albumin and sex-hormone-binding globulins, and serum free testosterone, which accounts for $1-2 \%$ of total serum testosterone, exhibits biological activity in humans (25). However, the mechanisms by which androgen affects adiponectin level have also not been determined, and there has been little investigation of the relationship between free testosterone and adiponectin levels.

In this study, we examined the association between aging and adiponectin level from the aspect of the influence of a decline of renal function or sex hormones in participants in mass-screening tests for residents in a region of Hokkaido, Japan.

\section{Subjects and methods}

Of 1519 participants in mass-screening tests for the residents of the towns Tanno and Sobetsu in Hokkaido, Japan, in 2003, 964 males and females with an average age of $60.3 \pm 12.5$ years ( 372 males with an average age of $62.8 \pm 12.4$ years and 592 females with an average age of $58.8 \pm 12.3$ years) were selected after exclusion of patients undergoing treatment for hypertension, diabetes and hyperlipidemia (subjects from the first selection), and 237 males and females with an average age of 58.3 \pm 16.2 years (123 males with an average age of $59.8 \pm 16.7$ years and 114 females with an average age of $56.6 \pm 15.6$ years) were randomly selected from seven 10-year age brackets (30s to 90s) in males and from six 10-year age brackets (30s to 80s) in females, with a maximum of 21 subjects from each bracket, after exclusion of patients undergoing treatment for hypertension, diabetes and hyperlipidemia (subjects from the second selection). Since the number of subjects in the 90 s bracket in males was only four, they were included in the 80 s bracket in males. Patients with reproductive organ disease that might affect sex hormones were not included in this study.

The mass-screening tests were carried out between 0600 and $0800 \mathrm{~h}$ in the morning. Height and body weight were measured before blood-pressure measurement, and blood was collected from the subjects under fasting conditions before breakfast. Blood pressure was measured more than once from the right arm after resting for several minutes in a sitting position, and the average was calculated. Blood was collected from the median cubital vein in a sitting position with a vacuum tube. The items measured were systolic blood pressure (SBP), diastolic blood pressure (DBP), BMI, FPG, total cholesterol, triglyceride, HDL, blood urea nitrogen (BUN), serum creatinine and serum adiponectin concentrations. Serum was stored in a freezer at $-20^{\circ} \mathrm{C}$. The frozen serum was used to measure testosterone and free testosterone concentrations in males and estrone (E1) and estradiol (E2) concentrations in females after 4 months. Biochemical data were assayed as follows: FPG, the glucose-oxidase electrode method; total cholesterol, the cholesterol oxidase enzymatic assay method; triglyceride, the enzymatic colorimetric method; HDL, the direct liquid-stable assay; BUN, urease- glutamate dehydrogenase method; serum creatinine, Jaffe reaction method; adiponectin, the sandwich ELISA method (human adiponectin ELISA kit; Otsuka Pharmaceutical Co., Tokyo, Japan); testosterone and free testosterone, solid-phase RIA method (Coat-A-Count TotalTestosterone and Coat-A-Count Free Testosterone Diagnostic Products Corp., Los Angeles, CA, USA); E1, the double-antibody RIA method (ESTRONE RIA; Diagnostic Systems Laboratories, Inc., Webster, TX, USA); and E2, solid-phase RIA method (Coat-A-Count Estradiol; Diagnostic Products Corp.). The minimum detectable values for testosterone, free testosterone, E1 and E2 were $<5.0 \mathrm{ng} / \mathrm{dl}(0.17 \mathrm{nM})$, $<0.5 \mathrm{pg} / \mathrm{ml}(1.73 \mathrm{pM}),<15.0 \mathrm{pg} / \mathrm{ml}(55.5 \mathrm{pM})$ and $<8.0 \mathrm{pg} / \mathrm{ml}(29.4 \mathrm{pM})$, respectively.

The subjects from the first selection were divided into two age groups, 65 years of age or older (Age $\geq 65$ group) and less than 65 years of age (Age $<65$ group), to compare indices in middle-aged and elderly subjects. Multiple-regression analysis was performed with adiponectin as a dependent variable for both data from subjects from the first selection and data from subjects from the second selection.

The present study was carried out in accordance with the Declaration of Helsinki (1981) of the World Medical Association, and the study protocol was approved by the Research Committee of Sapporo Medical University, Sapporo, Japan. Written, informed consent was obtained from each subject after full explanation of the purpose, nature and risk of all procedures used.

Statistical analysis was performed with Windows SPSS version 12.0 in Japanese (SPSS Japan). Since adiponectin showed an $F$ distribution, natural logarithmic-transformed values (LnAdipo) were used, and each value is presented as a mean \pm s.D. The unpaired $t$-test was used to compare data in two groups. A $P$ value of less than 0.05 was considered statistically significant.

\section{Results}

The characteristics of subjects from the first selection are shown in Table 1. Adiponectin concentrations were $6.02 \pm 3.33 \mu \mathrm{g} / \mathrm{ml}$ in males and $8.91 \pm 4.20 \mu \mathrm{g} / \mathrm{ml}$ in females, the concentration being significantly higher in females than in males. LnAdipo correlated positively with age, HDL and BUN and negatively with BMI, DBP, FPG, total cholesterol and triglyceride in males and correlated positively with age, HDL and BUN and negatively with BMI, FPG and triglyceride in females. Age, BMI, SBP, DBP, FPG, triglyceride, BUN and serum creatinine were 
Table 1 Background of subjects from the first selection (mean values and correlations related to adiponectin).

\begin{tabular}{|c|c|c|c|c|}
\hline & \multicolumn{2}{|c|}{ Males $(n=372)$} & \multicolumn{2}{|c|}{ Females $(n=592)$} \\
\hline & Mean \pm S.D. & $r$ & 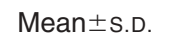 & $r$ \\
\hline Age (years) & $62.8 \pm 12.4^{*}$ & $0.359 \dagger$ & $58.8 \pm 12.3$ & $0.175 \dagger$ \\
\hline BMI $\left(\mathrm{kg} / \mathrm{m}^{2}\right)$ & $23.8 \pm 3.3^{*}$ & $-0.314 \dagger$ & $23.1 \pm 3.2$ & $-0.248 t$ \\
\hline $\mathrm{SBP}(\mathrm{mmHg})$ & $133.5 \pm 21.1^{*}$ & 0.020 & $129.2 \pm 23.2$ & 0.031 \\
\hline $\mathrm{DBP}(\mathrm{mmHg})$ & $75.9 \pm 11.9^{*}$ & $-0.120 \dagger$ & $73.0 \pm 12.2$ & -0.004 \\
\hline FPG (mg/dl) & $97.2 \pm 16.5^{\star}$ & $-0.122 \dagger$ & $93.3 \pm 16.4$ & $-0.200 \dagger$ \\
\hline TC (mg/dl) & $193.2 \pm 33.0 *$ & $-0.162 \dagger$ & $205.3 \pm 32.7$ & 0.038 \\
\hline TG (mg/dl) & $115.4 \pm 75.4^{*}$ & $-0.346 \dagger$ & $89.3 \pm 43.5$ & $-0.181 \dagger$ \\
\hline HDL (mg/dl) & $51.4 \pm 11.6^{\star}$ & $0.285 \dagger$ & $59.3 \pm 13.5$ & $0.201 \dagger$ \\
\hline BUN (mg/dl) & $16.5 \pm 4.1^{*}$ & $0.179 \dagger$ & $15.0 \pm 4.0$ & $0.147 \dagger$ \\
\hline $\mathrm{Cr}(\mathrm{mg} / \mathrm{dl})$ & $1.10 \pm 0.33^{*}$ & 0.082 & $0.89 \pm 0.26$ & 0.071 \\
\hline Adipo $(\mu \mathrm{g} / \mathrm{ml})$ & $6.02 \pm 3.33^{*}$ & & $8.91 \pm 4.20$ & \\
\hline
\end{tabular}

BMI, body mass index; SBP, systolic blood pressure; DBP, diastolic blood pressure; FPG, fasting plasma glucose; TC, total cholesterol; TG, triglyceride; HDL, high-density lipoprotein; BUN, blood urea nitrogen; $\mathrm{Cr}$, serum creatinine; Adipo, adiponectin.

$r$, versus LnAdipo, Pearson's correlation coefficient.

$* P<0.05$ versus females, unpaired $t$-test.

$\dagger P<0.05$ versus LnAdipo, Pearson's correlation.

Conversion factors: $\mathrm{FPG}, \mathrm{mM}=\mathrm{mg} / \mathrm{dl} \times 0.05551$; $\mathrm{TC}, \mathrm{mM}=\mathrm{mg} / \mathrm{dl} \times 0.02586$; $\mathrm{TG}, \quad \mathrm{mM}=\mathrm{mg} / \mathrm{dl} \times 0.01129 ; \quad \mathrm{HDL}, \quad \mathrm{mM}=\mathrm{mg} / \mathrm{dl} \times 0.02586 ; \quad \mathrm{BUN}, \quad \mathrm{mM}=$ $\mathrm{mg} / \mathrm{dl} \times 0.3570 ; \mathrm{Cr}, \mu \mathrm{M}=\mathrm{mg} / \mathrm{dl} \times 88.40$.

significantly higher in males than in females, and total cholesterol and HDL were significantly lower in males than in females.

The mean values of adiponectin and BUN in relation to age are shown in Figs 1 and 2. Adiponectin increased linearly with aging in males, whereas in females it increased sharply until the 50s age bracket with a convex curve and then increased gradually (Fig. 1). The patterns of changes in adiponectin were similar to the patterns of changes in BUN (Figs 1 and 2).

In multiple-regression analysis of sex differences, age, BMI, SBP, FPG, total cholesterol, triglyceride, HDL and BUN with LnAdipo as a dependent variable, BUN was selected as a significant independent variable as well as sex differences, age, BMI, FPG, triglyceride and HDL (Table 2). SBP, BUN and adiponectin were significantly higher and BMI and triglyceride were significantly lower in males in the Age $\geq 65$ group than in males in the Age $<65$ group, and BMI, SBP, DBP, FPG, total cholesterol, triglyceride, BUN, serum creatinine and adiponectin were significantly higher and HDL was significantly lower in females in the Age $\geq 65$ group than in females in the Age $<65$ group (Table 3). In males, BUN showed a positive correlation with adiponectin in the Age $\geq 65$ group $(r=0.219, P=0.002)$ but not in the Age $<65$ group. In females, BUN showed a stronger positive correlation with adiponectin in the Age $\geq 65$ group than in the Age $<65$ group $(r=0.134$, $P=0.045$ vs $r=0.128, P=0.014$; Table 3$)$. In multiple-regression analysis using LnAdipo as a dependent variable, BUN was selected as a significant independent variable along with sex differences, age, BMI, FPG, triglyceride and HDL in the Age $\geq 65$ group, while BUN was not selected as a significant independent variable in the Age $<65$ group (Table 4 ).

Characteristics of subjects from the second selection are shown in Table 5. Adiponectin concentrations were $6.26 \pm 3.94 \mu \mathrm{g} / \mathrm{ml}$ in males and $8.84 \pm 4.71 \mu \mathrm{g} / \mathrm{ml}$ in females, the concentration being significantly higher in females than in males. LnAdipo correlated positively with age and testosterone in males and negatively with BMI and free testosterone in males. There was no statistical gender-based difference in age, and BMI was significantly higher in males than in females.

The mean values of testosterone, free testosterone, E1 and E2 in relation to age are shown in Figs 3 and 4. In subjects from the second selection, the changes in mean values of adiponectin in relation to age were similar to those in subjects from the first selection (Fig. 1). In males, testosterone gradually decreased in their $30 \mathrm{~s}$
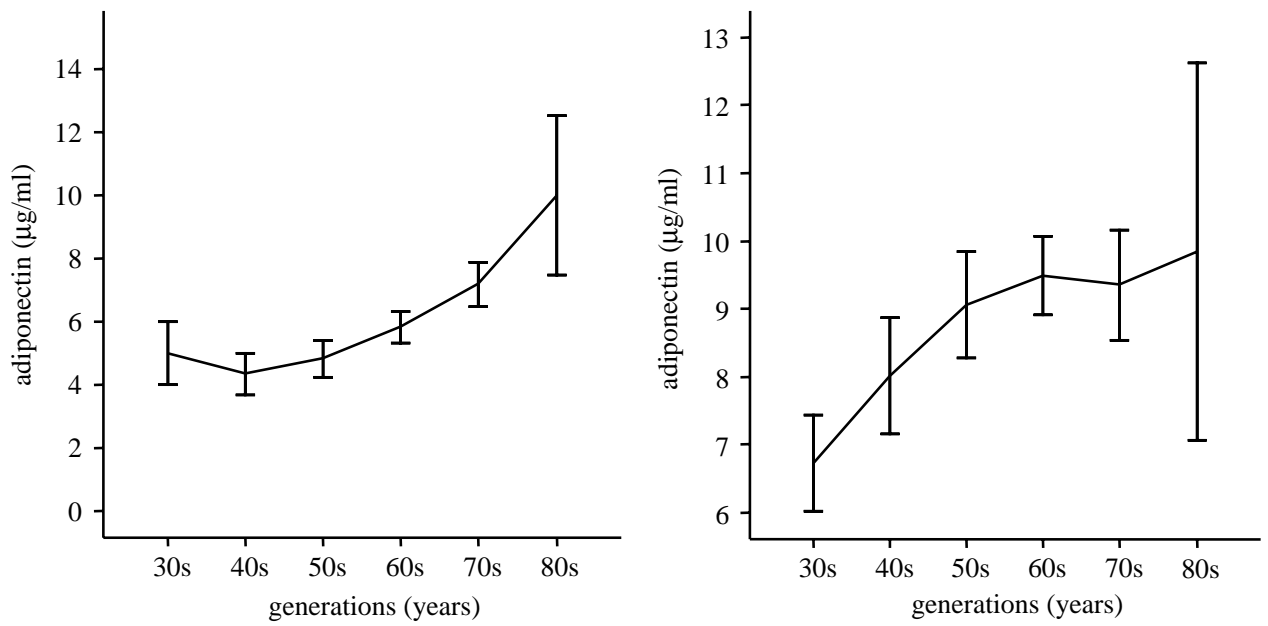

Figure 1 Mean plasma adiponectin levels for each generation in males and females. Numbers of male subjects in each age group were as follows: 30 s, $n=19$; 40s, $n=44$; 50 s, $n=62$; $60 \mathrm{~s}, n=130$; $70 \mathrm{~s}, n=96$; $80 \mathrm{~s}, n=21$. Numbers of female subjects: $30 \mathrm{~s}, n=53$; 40s, $n=88$; 50s, $n=129$; 60s, $n=209$; 70s, $n=104$; 80 s, $n=9$. 

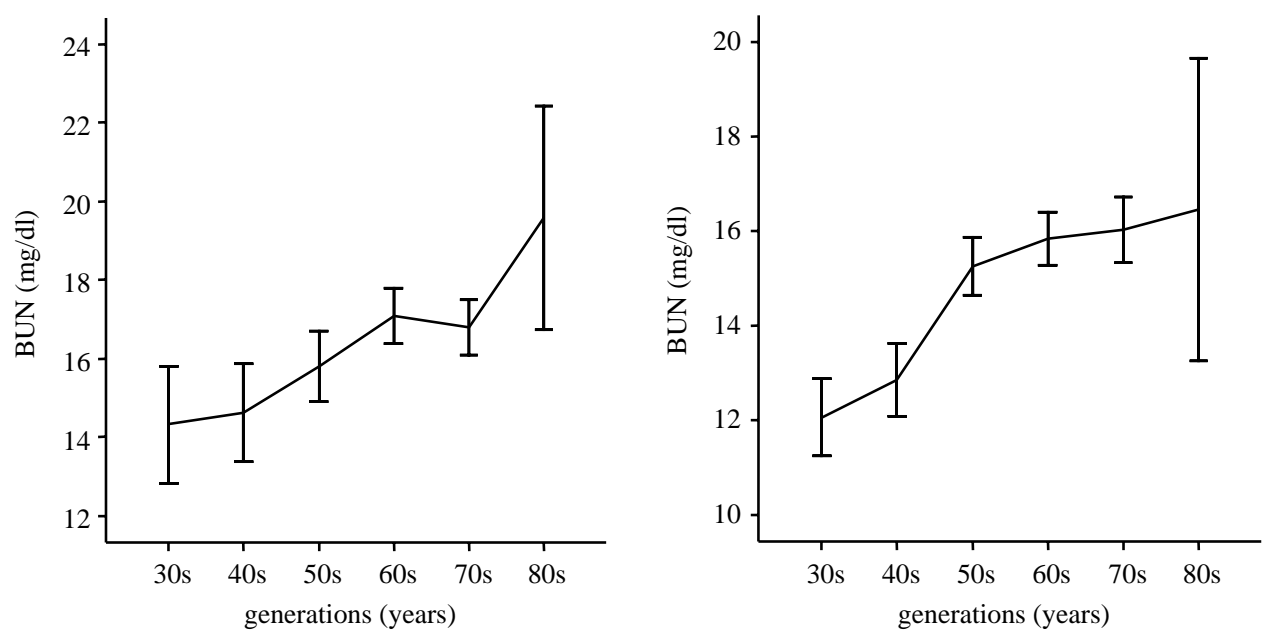

Figure 2 Mean BUN levels for each generation in males and females. Numbers of male and females subjects in each age group are given in the Fig. 1 legend. Conversion factor: $\mathrm{mM}=\mathrm{mg} / \mathrm{dl} \times 0.357$.

and free testosterone decreased almost linearly with aging, a pattern of change opposite to that of adiponectin (Fig. 3). In females, E1 and E2 sharply decreased up to the 50 s age bracket, in contrast to the pattern of change in adiponectin (Fig. 4).

In multiple-regression analysis of age, BMI and sex hormones with LnAdipo as a dependent variable, free testosterone, which exhibits biological activity in humans, was not selected as a significant independent variable, whereas age and BMI were selected as significant independent variables in males. In females, E1 and E2 were also not selected as significant independent variables (Table 6).

\section{Discussion}

Previous studies showed that there is an inverse relationship between adiponectin level and creatinine clearance in essential hypertensives (10) and that

Table 2 Results of multiple-regression analysis related to LnAdipo in subjects from the first selection.

\begin{tabular}{lrrrr}
\hline & $\boldsymbol{\beta}$ & $\boldsymbol{r}$ & $\mathbf{v}(\%)$ & $\boldsymbol{P}$ value \\
\hline Sex & 0.331 & 0.373 & 12.3 & $<0.001$ \\
Age & 0.240 & 0.170 & 4.1 & $<0.001$ \\
BMI & -0.170 & -0.291 & 4.9 & $<0.001$ \\
SBP & -0.002 & -0.010 & 0.0 & 0.946 \\
FPG & -0.131 & -0.197 & 2.6 & $<0.001$ \\
TC & -0.035 & 0.026 & 0.1 & 0.257 \\
TG & -0.140 & -0.318 & 4.5 & $<0.001$ \\
HDL & 0.139 & 0.312 & 4.3 & $<0.001$ \\
BUN & 0.086 & 0.078 & 0.7 & 0.002 \\
\hline
\end{tabular}

Sex, males $=0$, females $=1 ; \mathrm{BMI}$, body mass index; SBP, systolic blood pressure; FPG, fasting plasma glucose; TC, total cholesterol; TG, triglyceride; HDL, high-density lipoprotein; BUN, blood urea nitrogen; $\beta$, standardized regression coefficient; $r$, versus LnAdipo, Pearson's correlation; $\mathrm{V}$, variation of LnAdipo, calculated by $\beta \times r \times 100$ in absolute value. aggravated renal function is one of the reasons for increase an in adiponectin level with aging (23). Another previous study showed that adiponectin level is positively associated with abnormal renal function, assessed by urinary albumin-to-creatinine ratio, in patients with diabetes (24). These studies suggest that a decrease in adiponectin clearance in the kidney may be the cause of high levels of adiponectin in the elderly, although it is unlikely to be the sole mechanism. Previous studies have shown that renal function declines with aging (26-29) and BUN is known as an indicator of renal function. It has been reported that BUN level is affected by aging (30) and that there is a significant positive correlation between BUN level and age (31). Therefore, we used BUN level as an indicator of renal function in this study.

Adiponectin increased linearly with aging in males, whereas in females it increased sharply until the 50s age bracket with a convex curve and then increased gradually (Fig. 1). The patterns of changes in adiponectin were similar to the patterns of changes in BUN (Fig. 2). In multiple-regression analysis using LnAdipo as a dependent variable, BUN was selected as a significant independent variable as well as sex differences, age, BMI, FPG, triglyceride and HDL in all subjects (Table 2) and BUN was also selected as a significant independent variable in the Age $\geq 65$ group, whereas BUN was not selected as a significant independent variable in the Age $<65$ group (Table 4). These results suggest that decline of renal function with aging contributes independently to the elevation of adiponectin level. Since the biological significance of this elevation in adiponectin in the elderly is not known, further investigation is necessary to clarify the effects of increase in adiponectin in the elderly.

Studies conducted in Japan and other countries have demonstrated that sex hormone levels change with aging $(25,32-36)$. In Japan, the average age of 
Table 3 Unpaired $t$-test between data for subjects from the first selection in the Age $\geq 65$ and Age $<65$ groups and Pearson's correlation in each group.

\begin{tabular}{|c|c|c|c|c|c|c|c|c|}
\hline & \multicolumn{4}{|c|}{ Males } & \multicolumn{4}{|c|}{ Females } \\
\hline & \multicolumn{2}{|c|}{ Age $<65(n=171)$} & \multicolumn{2}{|c|}{ Age $\geq 65(n=201)$} & \multicolumn{2}{|c|}{ Age $<65(n=368)$} & \multicolumn{2}{|c|}{ Age $\geq 65(n=224)$} \\
\hline & Mean \pm S.D. & $r$ & Mean \pm S.D. & $r$ & Mean \pm S.D. & $r$ & Mean士S.D. & $r$ \\
\hline Age (years) & $52.1 \pm 9.2^{*}$ & $0.166 \dagger$ & $71.9 \pm 5.6$ & $0.288 \dagger$ & $51.5 \pm 9.5^{\star}$ & $0.202 \dagger$ & $70.7 \pm 4.6$ & 0.022 \\
\hline BMI $\left(\mathrm{kg} / \mathrm{m}^{2}\right)$ & $24.5 \pm 3.8^{*}$ & $-0.197 \dagger$ & $23.2 \pm 2.7$ & $-0.371 \dagger$ & $22.8 \pm 3.3^{\star}$ & $-0.215 \dagger$ & $23.6 \pm 3.1$ & $-0.349 \dagger$ \\
\hline $\mathrm{SBP}(\mathrm{mmHg})$ & $126.5 \pm 17.9 *$ & 0.073 & $139.3 \pm 21.9$ & $-0.175 \dagger$ & $121.8 \pm 19.7^{*}$ & -0.078 & $141.3 \pm 23.5$ & 0.083 \\
\hline $\mathrm{DBP}(\mathrm{mmHg})$ & $76.3 \pm 11.9$ & -0.004 & $75.6 \pm 12.0$ & $-0.208 \dagger$ & $71.7 \pm 11.8^{*}$ & $-0.107 \dagger$ & $75.2 \pm 12.6$ & 0.121 \\
\hline FPG (mg/dl) & $96.4 \pm 15.0$ & -0.071 & $97.9 \pm 17.6$ & $-0.193 \dagger$ & $91.9 \pm 17.8^{*}$ & $-0.227 \dagger$ & $95.8 \pm 13.6$ & $-0.189 \dagger$ \\
\hline $\mathrm{TC}(\mathrm{mg} / \mathrm{dl})$ & $194.8 \pm 32.2$ & $-0.163 \dagger$ & $191.9 \pm 33.6$ & $-0.150 \dagger$ & $200.1 \pm 33.6^{*}$ & 0.042 & $213.8 \pm 29.5$ & -0.025 \\
\hline $\mathrm{TG}(\mathrm{mg} / \mathrm{dl})$ & $131.4 \pm 94.3^{*}$ & $-0.306 \dagger$ & $101.7 \pm 50.8$ & $-0.348 \dagger$ & $83.6 \pm 42.9^{\star}$ & $-0.207 \dagger$ & $98.6 \pm 42.9$ & $-0.193 \dagger$ \\
\hline HDL (mg/dl) & $50.6 \pm 11.2$ & $0.310 \dagger$ & $52.1 \pm 12.0$ & $0.256 \dagger$ & $60.2 \pm 13.8^{*}$ & 0.204 & $57.7 \pm 13.1$ & $0.226+$ \\
\hline BUN (mg/dl) & $15.9 \pm 3.9^{*}$ & 0.045 & $17.0 \pm 4.2$ & $0.219 \dagger$ & $14.3 \pm 3.9^{*}$ & $0.128 \dagger$ & $16.0 \pm 3.8$ & $0.134 \dagger$ \\
\hline $\mathrm{Cr}(\mathrm{mg} / \mathrm{dl})$ & $1.07 \pm 0.12$ & -0.054 & $1.12 \pm 0.43$ & 0.094 & $0.87 \pm 0.10^{*}$ & 0.036 & $0.93 \pm 0.40$ & 0.090 \\
\hline Adipo $(\mu \mathrm{g} / \mathrm{ml})$ & $4.96 \pm 2.41^{*}$ & & $6.93 \pm 3.72$ & & $8.58 \pm 4.12^{*}$ & & $9.45 \pm 4.27$ & \\
\hline
\end{tabular}

Age $<65$ group, group of subjects aged less than 65 years; Age $\geq 65$ group, a group of subjects 65 years of age or older.

$\mathrm{BMI}$, body mass index; SBP, systolic blood pressure; DBP, diastolic blood pressure; FPG, fasting plasma glucose; TC, total cholesterol; TG, triglyceride; HDL, high-density lipoprotein; BUN, blood urea nitrogen; Cr, serum creatinine; Adipo, adiponectin.

$r$, versus LnAdipo, Pearson's correlation coefficient.

${ }^{*} P<0.05$ versus the group of subjects 65 years of age or older, unpaired $t$-test.

$\dagger P<0.05$ versus LnAdipo, Pearson's correlation.

Conversion factors: $\mathrm{FPG}, \mathrm{mM}=\mathrm{mg} / \mathrm{dl} \times 0.05551 ; \mathrm{TC}, \mathrm{mM}=\mathrm{mg} / \mathrm{dl} \times 0.02586 ; \mathrm{TG}, \mathrm{mM}=\mathrm{mg} / \mathrm{dl} \times 0.01129 ; \mathrm{HDL}, \mathrm{mM}=\mathrm{mg} / \mathrm{dl} \times 0.02586 ; \mathrm{BUN}, \mathrm{mM}=$ $\mathrm{mg} / \mathrm{dl} \times 0.3570 ; \mathrm{Cr}, \mu \mathrm{M}=\mathrm{mg} / \mathrm{dl} \times 88.40$.

menopause is about 50 years (35). It is known that the concentrations of adiponectin in the elderly are high $(21,22)$, but there has been little investigation of changes with aging. Investigation using mice revealed that androgens might inhibit the production of adiponectin (37) and that a decrease in sex hormones with aging might induce a gender difference in the process of elevation of adiponectin, because both testosterone and estrogen inhibited adiponectin, but the regulation by estrogen was weak and that by testosterone was strong (38). It has been reported that testosterone showed negative correlations with adiponectin in boys and that adiponectin levels decrease in parallel with the progression through puberty (39). Most of the subjects in the present study were middle-aged and elderly, and males tended to show a gradual decrease in testosterone in their 30s and an almost linear decrease in free testosterone from their 30s with aging (Fig. 3), whereas females showed a sharp drop in E1 and E2 in their 50s, the age of menopause (Fig. 4). Testosterone, free testosterone, E1 and E2 all changed with aging in manners consistent with previously reported findings $(25,32,36)$. Adiponectin tended to increase with aging in both males and females (Fig. 1) $(21,22)$. It tended to increase linearly with aging in males, while it sharply increased with a convex curve in females until their 50s, the age of menopause. The patterns of changes in adiponectin seem to be mirror images of changes in free testosterone in males and changes in E1 and E2 in females. However, in multiple-regression analysis of age, BMI and sex hormones with LnAdipo

Table 4 Results of multiple-regression analysis related to LnAdipo in subjects from the first selection in the Age $\geq 65$ and Age $<65$ groups.

\begin{tabular}{|c|c|c|c|c|c|c|c|c|}
\hline & \multicolumn{4}{|c|}{ Age $<65$ group } & \multicolumn{4}{|c|}{ Age $\geq 65$ group } \\
\hline & $\beta$ & $r$ & V (\%) & $P$ value & $\beta$ & $r$ & V (\%) & $P$ value \\
\hline Sex & 0.339 & 0.463 & 15.7 & $<0.001$ & 0.337 & 0.317 & 10.7 & $<0.001$ \\
\hline Age & 0.199 & 0.153 & 3.0 & $<0.001$ & 0.122 & 0.119 & 1.5 & 0.005 \\
\hline BMI & -0.119 & -0.281 & 3.3 & 0.003 & -0.248 & -0.317 & 7.9 & $<0.001$ \\
\hline SBP & -0.001 & -0.081 & 0.0 & 0.975 & -0.002 & -0.023 & 0.0 & 0.969 \\
\hline FPG & -0.145 & -0.216 & 3.1 & $<0.001$ & -0.109 & -0.202 & 2.2 & 0.010 \\
\hline $\mathrm{TC}$ & -0.027 & 0.015 & 0.0 & 0.522 & -0.037 & 0.024 & 0.1 & 0.445 \\
\hline TG & -0.153 & -0.353 & 5.4 & $<0.001$ & -0.106 & -0.271 & 2.9 & 0.027 \\
\hline HDL & 0.140 & 0.345 & 4.8 & 0.001 & 0.131 & 0.291 & 3.8 & 0.007 \\
\hline BUN & 0.046 & 0.006 & 0.0 & 0.231 & 0.127 & 0.127 & 1.6 & 0.003 \\
\hline
\end{tabular}

Age $<65$ group, a group of subjects aged less than 65 years; Age $\geq 65$ group, a group of subjects 65 year of age or older; Sex, males $=0$, females $=1$; BMI, body mass index; SBP, systolic blood pressure; FPG, fasting plasma glucose; TC, total cholesterol; TG, triglyceride; HDL, high-density lipoprotein; BUN, blood urea nitrogen; $\beta$, standardized regression coefficient; $r$, versus LnAdipo, Pearson's correlation; V, variation of LnAdipo, calculated by $\beta \times r \times 100$ in absolute value. 
Table 5 Background of subjects from the second selection (mean values and correlation related to adiponectin).

\begin{tabular}{|c|c|c|c|c|}
\hline & \multicolumn{2}{|c|}{ Males $(n=123)$} & \multicolumn{2}{|c|}{ Females $(n=114)$} \\
\hline & Mean士S.D. & $r$ & Mean \pm S.D. & $r$ \\
\hline Age (years) & $59.8 \pm 16.7$ & $0.405 \dagger$ & $56.6 \pm 15.6$ & 0.182 \\
\hline BMI $\left(\mathrm{kg} / \mathrm{m}^{2}\right)$ & $23.9 \pm 3.4^{*}$ & $-0.364 \dagger$ & $22.6 \pm 3.4$ & -0.138 \\
\hline $\mathrm{T}(\mathrm{ng} / \mathrm{dl})$ & $425.0 \pm 152.7$ & $0.183 \dagger$ & - & - \\
\hline Free T $(\mathrm{pg} / \mathrm{ml})$ & $18.32 \pm 6.95$ & $-0.182 \dagger$ & - & - \\
\hline $\mathrm{E} 1(\mathrm{pg} / \mathrm{ml})$ & - & - & $37.2 \pm 30.3$ & -0.129 \\
\hline E2 (pg/ml) & - & - & $58.9 \pm 76.3$ & -0.100 \\
\hline Adipo $(\mu \mathrm{g} / \mathrm{ml})$ & $6.26 \pm 3.94^{*}$ & & $8.84 \pm 4.71$ & \\
\hline
\end{tabular}

$\mathrm{BMI}$, body mass index; $\mathrm{T}$, testosterone; free $\mathrm{T}$, free testosterone; $\mathrm{E} 1$, estrone; E2, estradiol.

$r$, versus LnAdipo, Pearson's correlation coefficient; -, unavailable.

${ }^{*} P<0.05$ versus females, unpaired $t$-test.

† $P<0.05$ versus LnAdipo, Pearson's correlation.

Conversion factors: $\mathrm{T}, \mathrm{nM}=\mathrm{ng} / \mathrm{dl} \times 0.03467$; free $\mathrm{T}, \mathrm{pM}=\mathrm{pg} / \mathrm{ml} \times 3.467$; $\mathrm{E} 1, \mathrm{pM}=\mathrm{pg} / \mathrm{ml} \times 3.699 ; \mathrm{E} 2, \mathrm{pM}=\mathrm{pg} / \mathrm{ml} \times 3.671$.

as a dependent variable, free testosterone, which exhibits biological activity in humans, was not selected as a significant independent variable, whereas age and BMI were selected in males. In females, E1 and E2 were also not selected as significant independent variables (Table 6). These results indicate that the influence of bioactive sex hormones on changes in values of adiponectin with aging is not clear compared with the influence of decline of renal function on changes in values of adiponectin with aging.

One limitation in this study is the inconsistent timing of blood collection from premenopausal females, because samples were obtained from subjects undergoing periodical check-ups. For examination of female hormones in premenopausal females, blood should be collected at a certain time point of the menstrual period, such as the follicular phase (40) or luteal phase $(41,42)$, but there is a limitation to this in the setting of mass-screening tests. However, none of the enrolled females had a past history of gynecological disease, and since it was confirmed that E1 and E2 changed with aging in a pattern consistent with that reported previously, as shown in Fig. 4 (36), it is thought that the results reflect general changes in female sex hormones. Another limitation is that this investigation was a cross-sectional study. Therefore, more prospective studies may be necessary to clarify the relationship between aging and adiponectin.

In summary, we investigated the change in human adiponectin with aging separately in males and females and showed that there is a gender difference in the process of elevation of adiponectin. We also confirmed changes with aging in BUN in males and females and testosterone and free testosterone in males and E1 and E2 in females, which are consistent with findings reported previously $(25,32,36)$. The patterns of changes in adiponectin were similar to patterns of changes in BUN and seemed to be a mirror image of patterns of changes in free testosterone, E1 and E2 on a graph. However, multiple-regression analysis showed that the decline of renal function with aging seemed to be more involved in the elevation of adiponectin with aging than were changes with aging in these sex hormones. In humans, especially in the elderly, a decrease in adiponectin clearance due to a slight decline of renal function with aging, assessed by the BUN levels, may cause increase in serum adiponectin concentrations. On the other hand, it may be because androgen inhibits the production of adiponectin that adiponectin is lower in males than in females (37). Therefore, in terms of the increase in adiponectin with aging in the elderly, adiponectin seems to be influenced more strongly by BUN than by sex hormones
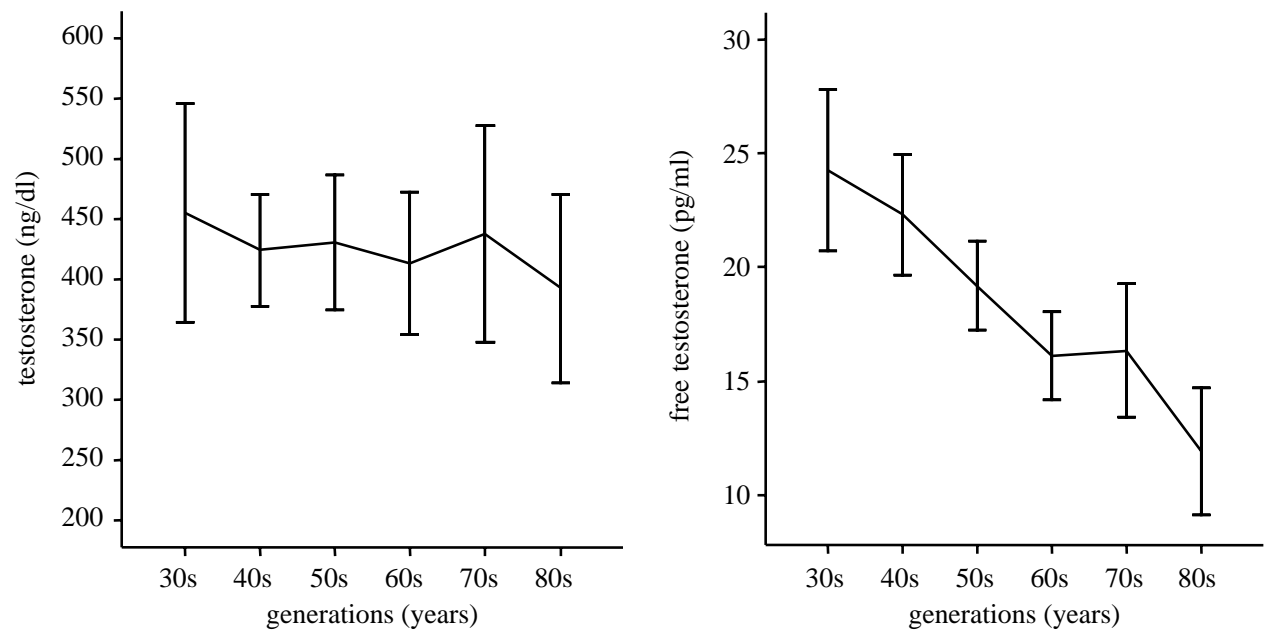

Figure 3 Mean plasma testosterone and free testosterone levels in males for each generation. Numbers of male subjects: 30 s, $n=19$; $40 \mathrm{~s}, n=21 ; 50 \mathrm{~s}, n=21 ; 60 \mathrm{~s}, n=21 ; 70 \mathrm{~s}, n=21 ; 80 \mathrm{~s}, n=20$. Conversion factors: testosterone, $\mathrm{nM}=\mathrm{ng} / \mathrm{dl} \times 0.03467$; free testosterone, $\mathrm{pM}=\mathrm{pg} / \mathrm{ml} \times 3.467$. 

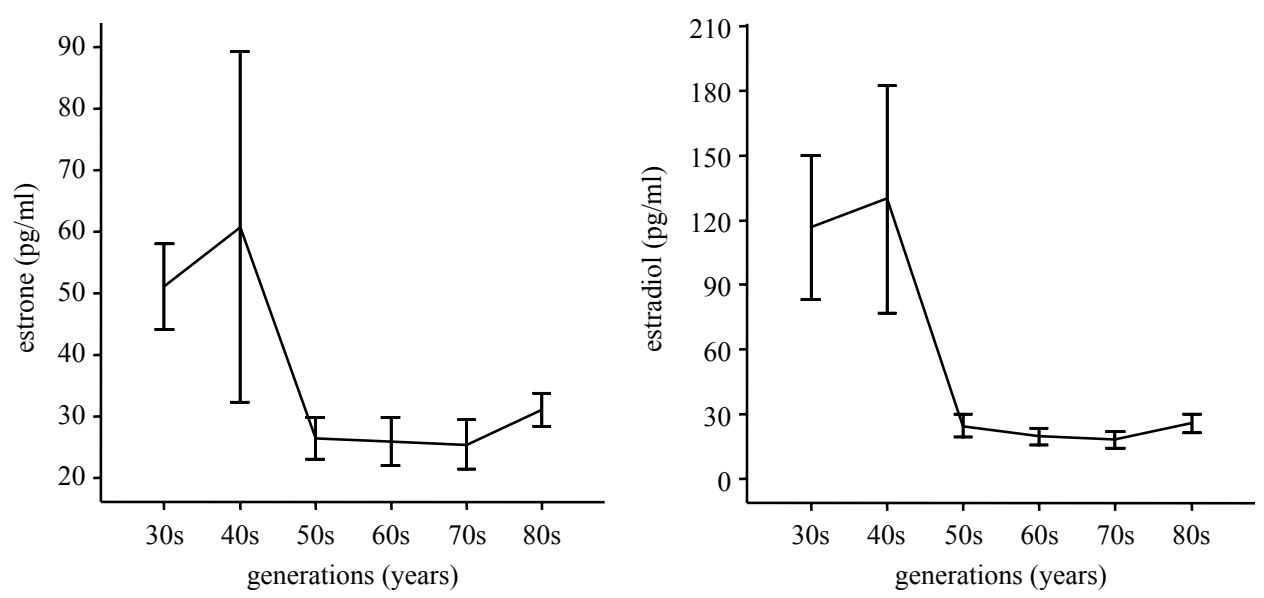

Figure 4 Mean plasma estrone (E1) and estradiol (E2) levels in females for each generation. Numbers of female subjects: 30s, $n=21$; $40 \mathrm{~s}, n=21$; $50 \mathrm{~s}, n=21$; $60 \mathrm{~s}, n=21 ; 70 \mathrm{~s}, n=21 ; 80 \mathrm{~s}, n=9$. Conversion factors: estrone, $\mathrm{pM}=\mathrm{pg} / \mathrm{ml} \times 3.699$; estradiol, $\mathrm{pM}=$ $\mathrm{pg} / \mathrm{ml} \times 3.671$.

Table 6 Results of multiple-regression analysis related to LnAdipo in subjects from the second selection.

\begin{tabular}{|c|c|c|c|c|c|c|c|c|c|}
\hline & \multicolumn{4}{|c|}{ Males $(n=123)$} & & \multicolumn{4}{|c|}{ Females $(n=114)$} \\
\hline & $\beta$ & $r$ & V (\%) & $P$ value & & $\beta$ & $r$ & V (\%) & $P$ value \\
\hline Age & 0.374 & 0.405 & 15.1 & $<0.001$ & Age & 0.200 & 0.182 & 3.6 & 0.050 \\
\hline BMI & -0.253 & -0.364 & 9.2 & 0.002 & BMI & -0.176 & -0.138 & 2.4 & 0.067 \\
\hline $\mathrm{T}$ & 0.197 & 0.183 & 3.6 & 0.015 & E1 & -0.052 & -0.129 & 0.7 & 0.601 \\
\hline Age & 0.418 & 0.405 & 16.9 & $<0.001$ & Age & 0.225 & 0.182 & 4.1 & 0.045 \\
\hline $\mathrm{BMI}$ & -0.301 & -0.364 & 11.0 & $<0.001$ & $\mathrm{BMI}$ & -0.180 & -0.138 & 2.5 & 0.060 \\
\hline Free $\mathrm{T}$ & 0.134 & -0.182 & 2.4 & 0.177 & E2 & 0.017 & -0.100 & 0.2 & 0.875 \\
\hline
\end{tabular}

BMI, body mass index; T, testosterone; free T, free testosterone; E1, estrone; E2, estradiol; $\beta$, standardized regression coefficient; $r$, versus LnAdipo, Pearson's correlation; V, variation of LnAdipo, calculated by $\beta \times r \times 100$ in absolute value.

and to be increased by a decline in renal function with aging.

\section{References}

1 Maeda K, Okubo K, Shimomura I, Funahashi T, Matsuzawa Y \& Matsubara K. cDNA cloning and expression of a novel adipose specific collagen-like factor, apM1 (adipose most abundant gene transcript 1). Biochemical and Biophysical Research Communications $1996221286-289$.

2 Scherer PE, Williams S, Fogliano M, Baldini G \& Lodish HF. A novel serum protein similar to $\mathrm{C} 1 \mathrm{q}$, produced exclusively in adipocytes. Journal of Biological Chemistry $1995 \quad \mathbf{2 7 0}$ 26746-26749.

3 Arita Y, Kihara S, Ouchi N, Takahashi M, Maeda K, Miyagawa J et al. Paradoxical decrease of an adipose-specific protein, adiponectin, in obesity. Biochemical and Biophysical Research Communications $1999 \mathbf{2 5 7} 79-83$.

4 Tsao TS, Murrey HE, Hug C, Lee DH \& Lodish HF. Oligomerization state-dependent activation of $\mathrm{KF}-\mathrm{\kappa B}$ signaling pathway by adipocyte complement-related protein of $30 \mathrm{kDa}$ (Acrp30). Journal of Biological Chemistry $200227729359-29362$.

5 Berg AH, Combs TP \& Scherer PE. Acrp30/adiponectin: an adipokine regulating glucose and lipid metabolism. Trends in Endocrinology and Metabolism 200213 84-89.

6 Chandran M, Phillips SA, Ciaraldi T \& Henry RR. Adiponectin: more than just another fat cell hormone? Diabetes Care 2003 $262442-2450$.
7 Waki H, Yamauchi T, Kamon J, Ito Y, Uchida S, Kita S, Hara K, Hada Y, Vasseur F, Froguel P, Kimura S, Nagai R \& Kadowahi T. Impaired multimerization of human adiponectin mutants associated with diabetes. Journal of Biological Chemistry $2003 \mathbf{2 7 8}$ 40352-40363.

8 Tsao TS, Tomas E, Murrey HE, Hug C, Lee DH, Ruderman NB, Heuser JE \& Lodish HF. Role of disulfide bonds in Acrp30/Adiponectin structure and signaling specificity. Journal of Biological Chemistry $2003 \mathbf{2 7 8} 50810-50817$.

9 Kobayashi H, Ouchi N, Kihara S, Walsh K, Kumada M, Abe Y, Funahashi T \& Matsuzawa Y. Selective suppression of endothelial cell apoptosis by the high molecular weight form of adiponectin. Circulation Research 200494 e27-e31.

10 Mallamaci F, Zoccali C, Cuzzola F, Tripepi G, Cutrupi S, Parlongo S, Tanaka S, Ouchi N, Kihara S, Funahashi T \& Matsuzawa Y Adiponectin in essential hypertension. Journal of Nephrology 2002 15 507-511.

11 Adamczak M, Więcek A, Funahashi T, Chudek J, Kokot F \& Matsuzawa Y. Decreased plasma adiponectin concentration in patients with essential hypertension. American Journal of Hypertension $2003 \mathbf{1 6} 72-75$.

12 Matsubara M, Maruoka S \& Katayose S. Decreased plasma adiponectin concentrations in women with dyslipidemia. Journal of Clinical Endocrinology and Metabolism 200287 2764-2769.

13 Zietz B, Herfarth H, Paul G, Ehling A, Müller-Ladner U, Schölmerich J \& Schäffler A. Adiponectin represents an independent cardiovascular risk factor predicting serum HDLcholesterol levels in type 2 diabetes. FEBS Letters $2003 \mathbf{5 4 5}$ 103-104. 
14 Lindsay RS, Funahashi T, Hanson RL, Matsuzawa Y, Tanaka S, Tataranni PA, Knowler WC \& Krakaff J. Adiponectin and development of type 2 diabetes in the Pima Indian population. Lancet $200236057-58$.

15 Hotta K, Funahashi T, Arita Y, Takahashi M, Matsuda M, Okamoto Y, Iwahashi H, Kuriyama H, Ouchi N, Maeda K, Nishida M, Kihara S, Sakai N, Nakajima T, Hasegawa K, Mavaguchi M, Ohmoto Y. Nakamura T, Yamashita S, Hanapusa T \& Matsuzawa Y Plasma concentrations of a novel, adipose-specific protein, adiponectin, in type 2 diabetic patients. Arteriosclerosis, Thrombosis, and Vascular Biology 200020 1595-1599.

16 Maeda N, Shimomura I, Kishida K, Nishizawa H, Matsuda M, Nagaretani H, Furumyaa, N, Kondo H, Takahashi M, Arita Y, Komuro R, Ouchi N, Kihara S, Tochino Y, Okutomi K, Horie M, Takeda S, Aoyama T, Funahashi T \& Matsuzawa Y. Diet-induced insulin resistance in mice lacking adiponectin/ACRP30. Nature Medicine 20028 731-737.

17 Hotta K, Funahashi T, Bodkin NL, Ortmeyer HK, Arita Y, Hansen BC \& Matsuzawa Y. Circulating concentrations of the adipocyte protein adiponectin are decreased in parallel with reduced insulin sensitivity during the progression to type 2 diabetes in rhesus monkeys. Diabetes 200150 1126-1133.

18 Weyer C, Funahashi T, Tanaka S, Hotta K, Matsuzawa Y, Pratley RE \& Tataranni PA. Hypoadiponectinemia in obesity and type 2 diabetes: close association with insulin resistance and hyperinsulinemia. Journal of Clinical Endocrinology and Metabolism 200186 1930-1935.

19 Yamamoto Y, Hirose H, Saito I, Tomita M, Taniyama M, Matsubara K, Okazaki Y, Ishii T, Nishikai T \& Saruta T. Correlation of the adipocyte-derived protein adiponectin with insulin resistance index and serum high-density lipoprotein-cholesterol, independent of body mass index, in the Japanese population. Clinical Science $2002 \mathbf{1 0 3} 137-142$.

20 Möhlig M, Wegewitz U, Osterhoff M, Isken F, Ristow M, Pfeiffer AFH \& Spranger J. Insulin decreases human adiponectin plasma levels. Hormone and Metabolic Research 200234 655-658.

21 Cnop M, Havel PJ, Utzschneider KM, Carr DB, Sinha MK, Boyko EJ, Retzlaft BM, Knopp RM, Brunzell JD \& Khan SE. Relationship of adiponectin to body fat distribution, insulin sensitivity and plasma lipoproteins: evidence for independent roles of age and sex. Diabetologia $2003 \mathbf{4 6}$ 459-469.

22 Isobe T, Saitoh S, Takagi S, Ohnishi H, Ohhata J, Takeuchi H, Fujiwara T, Higashiwa K, Ura N \& Shimamoto K. Adiponectin levels and coronary risk factors in the elderly. Japanese Journal of Geriatrics $200441328-333$.

23 Zoccali C, Mallamaci F, Tripepi G, Benedetto FA, Cutrupi S, Parlongo S, Malatino LS, Bonanno G, Seminara G, Rapisada F, Fatuzzo P, Bueni M, Nicocia G, Tanaka S, Ouchi N, Kihara S, Funahashi T \& Matsuzawa Y. Adiponectin, metabolic risk factors, and cardiovascular events among patients with end-stage rena disease. Journal of the American Society of Nephrology 200213 134-141.

24 Looker HC, Krakoff J, Funahashi T, Matsuzawa Y, Tanaka S, Nelson RG, Knowler WC, Lindsay RS \& Hanson RL. Adiponectin concentrations are influenced by renal function and diabetes duration in Pima Indians with type 2 diabetes. Journal of Clinical Endocrinology and Metabolism 200489 4010-4017.

25 Itoh N, Kumamoto Y, Akagashi K, Maruta H, Tsukamoto T, Umehara T, Mikuma N, Yamaguchi Y, Nanbu A \& Suzuhi N. The assessment of bioavailable androgen levels from the serum free testosterone level. Folia Endocrinologica Japonica 199167 $23-32$.

26 Davies DF \& Shock NW. Age changes in glomerular filtration rate, effective renal plasma flow, and tubular excretory capacity in adult males. Journal of Clinical Investigation 195029 496-507.
27 Friedman SA, Raizner AE, Rosen H, Solomon NA \& Sy W. Functional defects in the aging kidney. Annals of Internal Medicine $19727641-45$.

28 Epstein M. Aging and the kidney: clinical implications. Physician $198531123-137$.

29 Friedman JR, Norman DC \& Yoshikawa TT. Correlation of estimated renal function parameters versus 24-hour creatinine clearance in ambulatory elderly. Journal of the American Society of Nephrology 198937 145-149.

30 Lewis WH Jr \& Alving AS. Changes with age in the renal function in adult men. American Journal of Physiology 1938123 500-515.

31 Aono T, Matsubayashi K, Kawamoto A, Kimura S, Doi Y \& Ozawa T. Normal ranges of blood urea nitrogen and serum creatinine levels in the community-dwelling elderly subjects aged 70 years or over-correlation between age and renal function. Japanese Journal of Geriatrics $199431232-236$.

32 Gray A, Feldman HA, McKinlay JB \& Longcope C. Age, disease, and changing sex hormone levels in middle-aged men: results of the Massachusetts Male Aging Study. Journal of Clinical Endocrinology and Metabolism 199173 1016-1025.

33 Neaves WB, Johnson L, Porter JC, Parker CR Jr \& Petty CS. Leydig cell numbers, daily sperm production, and serum gonadotropin levels in aging men. Journal of Clinical Endocrinology and Metabolism $198459756-763$.

34 Miyao M \& Ouchi Y. Age related change of gonadal function. Sogo rinsho $2003 \mathbf{5 2} 259-266$.

35 Japan Society of Obstetrics and Gynecology, Report of the average age of menopause in Japan. Acta obstet gynaec Jpn $199547449-451$.

36 Akasofu K, Araki K \& Nishida E. Age-related change of the endocrine system. In SanfujinkaMOOK 30, pp 65-73. Ed. T Tamada. Tokyo: Kanahara, 1985.

37 Nishizawa H, Shimomura I, Kishida K, Maeda N, Kuriyama H, Nagaretani H, Matsuda M, Kondo H, Furuyama N, Kihara S, Nakamura T, Tochino Y, Funahashi T \& Matsuzawa N. Androgens decrease plasma adiponectin, an insulin-sensitizing adipocytederived protein. Diabetes $2002512734-2741$.

38 Combs TP, Berg AH, Rajala MW, Klebanov S, Iyengar P, JimenezChillaron JC, Patti ME, Klein SL, Weinstein RS \& Scherer PE. Sexual differentiation, pregnancy, calorie restriction, and aging affect the adipocyte-specific secretory protein adiponectin. Diabetes 200352 268-276.

39 Böttner A, Kratzsch J, Müller G, Kapellen TM, Blüher S, Keller E, Bluher M \& Keiss W. Gender differences of adiponectin levels develop during the progression of puberty and are related to serum androgen levels. Journal of Clinical Endocrinology and Metabolism 200489 4053-4061.

40 Smith S, Ravnikar VA \& Barbieri RL. Androgen and insulin response to an oral glucose challenge in hyperandrogenic women. Fertility and Sterility $1987 \mathbf{4 8} 72-77$.

41 Nestler JE, Clore JN, Strauss JF III \& Blackard WG. The effects of hyperinsulinemia on serum testosterone, progesterone, dehydroepiandrosterone sulfate, and cortisol levels in normal women and in a woman with hyperandrogenism, insulin resistance, and acanthosis nigricans. Journal of Clinical Endocrinology and Metabolism 198764 180-184.

42 Bolelli G, Muti P, Micheli A, Sciajno R, Franceschetti F, Krogh V, Pisani P \& Berrino F. Validity for epidemiological studies of long-term cryoconservation of steroid and protein hormones in serum and plasma. Cancer Epidemiology, Biomarkers and Prevention $19954509-513$.

Received 8 December 2004

Accepted 22 March 2005 